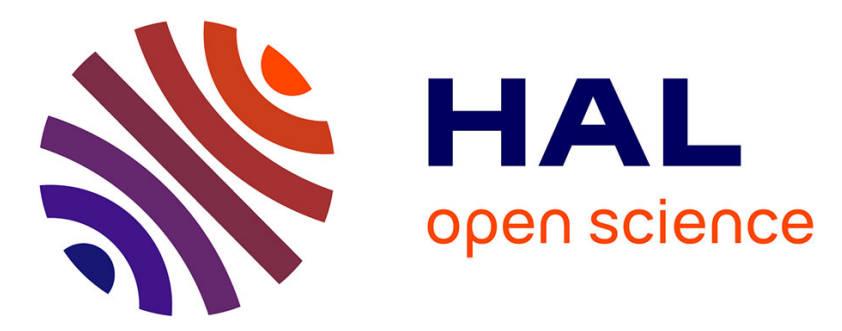

\title{
Curve Fitting Derivative Method and Its Application in Mouse Growth
}

Zhihua Li, Xin Zhao

\section{To cite this version:}

Zhihua Li, Xin Zhao. Curve Fitting Derivative Method and Its Application in Mouse Growth. 11th International Conference on Computer and Computing Technologies in Agriculture (CCTA), Aug 2017, Jilin, China. pp.126-133, 10.1007/978-3-030-06137-1_13 . hal-02124263

\section{HAL Id: hal-02124263 \\ https://hal.inria.fr/hal-02124263}

Submitted on 9 May 2019

HAL is a multi-disciplinary open access archive for the deposit and dissemination of scientific research documents, whether they are published or not. The documents may come from teaching and research institutions in France or abroad, or from public or private research centers.
L'archive ouverte pluridisciplinaire HAL, est destinée au dépôt et à la diffusion de documents scientifiques de niveau recherche, publiés ou non, émanant des établissements d'enseignement et de recherche français ou étrangers, des laboratoires publics ou privés.

\section{(c)(1)}

Distributed under a Creative Commons Attribution| 4.0 International License 


\title{
Curve Fitting Derivative Method and Its Application in Mouse Growth
}

\author{
Zhihua $\mathrm{Li}^{1}$, Xin Zhao ${ }^{(\mathbb{\varpi}) 1}$ \\ ${ }^{1}$ College of Information Technology, Jilin Agricultural University \\ Changchun 130118, China \\ 814155716@qq.com, jlndzx@sina.com.
}

\begin{abstract}
Goal] Exploring change rules of the mouse growth, providing genetic data for the prediction and production of genetic analysis in scientific research and basic data for the standards of laboratory animals.[Method] Mice were weighed at 10 time points, including 3,4, 5, 6, 7, 8, 9, 10, 11, 12 weeks of age, and the corresponding data were recorded. Both general and derivative methods of Gompertz curve parameter estimation were used to analyze the mice. Then, the parameter values and the fitting degree $\left(R^{2}\right)$ were calculated. [Result] The derivative method has the highest $R^{2}$ (0.993734), followed by the three-point method $R^{2}$ (0.990689). [Conclusion] The derivative method of Gompertz curve parameter estimation has the best effect on mouse fitting and can be used for the estimation and prediction of mouse growth.
\end{abstract}

Keywords: Mouse growth; Parameter estimation; Curve fitting; Derivative method.

\section{Introduction}

* College of Information Technology, Jilin Agricultural University, Changchun City, Jilin Province 
The analysis of animal growth curve is one of the main methods to study the law of animal growth and development. It can describe the regularity and continuity of body weight as it increases with age. The essence of the growth curve analysis is to compress a series of age-weight data into several parameters in the growth mathematical model, effectively eliminate the influence of some experimental errors, and have very practical reference significance [1].

At present, the commonly used growth models are Logistic, Gompertz and Bertanlanffy fitting equations $[2,3,4]$. Through the analysis of experimental animal growth curve, not only can dynamically understand the growth process of animals and predict the law of animal growth, but also can guide the management of breeders and improve the breeding effect. In the breeding of laboratory animals, we found that there were some differences in the quality of animals in different regions and different animal lines, and individual differences were observed in animal experiments. To this end, this article based on different gender animal body weight and age of the relationship between the experimental study and analysis [5,6].

By estimating the general method of Gompertz curve parameter estimation and the pre-statistical analysis of Gompertz curve parameter estimation derivative method, the parameter estimation and fitting degree $R^{2}$ and Gompertz curve parameter estimation derivative model are more suitable for the growth curve fitting, in this paper, Gompertz curve parameter estimation derivative model was used to analyze the mice.

\section{Materials}

Materials experimental animals were randomly divided into groups, free feeding and drinking water for feeding, Mice were weighed at 3, 4, 5, 6, 7, 8, 10, 9, 10, 11 and 12 weeks of age, and record the data as shown in Table 1 below.

Table 1. 3 to 12 Weeks old mice body mass data [7].

\begin{tabular}{ccccccccccc}
\hline Week age $/ \mathrm{t}$ & 3 & 4 & 5 & 6 & 7 & 8 & 9 & 10 & 11 & 12 \\
\hline Body mass $/ \mathrm{y}$ & 44.3 & 82.9 & 122.8 & 151.5 & 172.5 & 210.4 & 227.3 & 242.5 & 255.3 & 262.9 \\
\hline
\end{tabular}

\section{Methods}

\subsection{A General Method of Gompertz Curve Parameter Estimation}

$$
y=a e^{-b e^{-c t}}
$$

Pairs of upper ends are obtained by logarithms:

$$
\ln \ln \frac{a}{y}=\ln b e^{-c t}
$$

Make: 


$$
Y=\ln \ln \frac{a}{y} \text { 回 } \mathrm{A}=\operatorname{lnb}, \mathrm{B}=-\mathrm{c}
$$

Then the above formula becomes:

$$
\frac{d Y}{d x}=\frac{1}{\ln \frac{a}{y}} \frac{a}{y}\left(-\frac{a}{y^{2}}\right)=-\frac{y}{y \ln \frac{a}{y}}=-\frac{1}{y(\ln a-\ln y)}
$$

By the least squares method:

$$
\left\{\begin{array}{c}
A=\bar{Y}-B \bar{X} \\
B=\frac{\sum_{i=1}^{n} X_{i} Y_{i}-\frac{1}{n}\left(\sum_{i=1}^{n} X_{i}\right)\left(\sum_{i=1}^{n} Y_{i}\right)}{\sum_{i=1}^{n} X_{i}^{2}-\frac{1}{n}\left(\sum_{i=1}^{n} X_{i}\right)^{2}}
\end{array}\right.
$$

\subsection{Parameter estimation of a value}

Three point method

First change the equation (1) to:

$$
\frac{y}{a}=e^{-b e^{-c t}}
$$

On both sides of the above pairs of logarithm:

$$
\ln \frac{y}{a}=-b e^{-c t}
$$

And then on both sides of the above pairs of logarithm:

$$
\ln \ln \frac{a}{y}=\ln b-c t
$$

Select the starting point, midpoint, and end point in the measured data, $\left(t_{1}, y_{1}\right),\left(t_{2}, y_{2}\right),\left(t_{3}, y_{3}\right)$ and then the three points into the above formula:

$$
\begin{aligned}
& \ln \ln \frac{a}{y_{1}}=\ln b-c t_{1} \\
& \ln \ln \frac{a}{y_{2}}=\ln b-c t_{2} \\
& \ln \ln \frac{a}{y_{3}}=\ln b-c t_{3}
\end{aligned}
$$

Because $2 t_{2}=t_{1}+t_{3}$, eliminate $\mathrm{b}$ and $\mathrm{c}$ get a dollar equation:

$$
2 \ln \ln \frac{a}{y_{2}}=\ln \ln \frac{a}{y_{1}}+\ln \ln \frac{a}{y_{3}}
$$

Solve the equation (7) to obtain the value of the three-point method to estimate the expression:

$$
\ln a=\frac{\ln y_{1} \ln y_{3}-\left(\ln y_{2}\right)^{2}}{\ln y_{1}+\ln y_{3}-2 \ln y_{2}}
$$




\subsection{The derivative method of Gompertz curve parameter estimation}

$$
y=a e^{-b e^{-c t}}
$$

Gompertz is a commonly used growth curve, which occupies a certain position in the econometric economy. Where $e$ is the bottom of the natural logarithm, and $a$, $b$, and $\mathrm{c}$ are positive parameters. Its distribution is a S-shaped growth curve, the expression of the two ends of the natural logarithm:

$$
\ln y=\ln a-b e^{-c t}
$$

On (10) at both ends of the derivative on $t$ :

$$
\frac{1}{y} \frac{d y}{d t}=b c e^{-c t}
$$

(11) where $\mathrm{d}=\mathrm{bc}, \quad Y=\frac{1}{y} \frac{d y}{d t}$, then (11):

$$
Y=d e^{-c t}
$$

(12) is an exponential function model with only two parameters of d and c. In order to estimate the parameters $d$ and $c$ of (12), we can take the natural logarithm at (12):

$$
\ln Y=\ln d-c t
$$

Let $Z=\ln Y, A=\ln d, B=-c$ (13) into a linear model:

$$
Z=A+B t
$$

The parameters B and A in (14) can be estimated by the least squares method:

$$
\left\{\begin{array}{c}
\hat{A}=\bar{Z}-\hat{B} \bar{t} \\
B=\frac{\sum_{i=1}^{n}\left(t_{i}-\bar{t}\right)\left(Z_{i}-\bar{Z}\right)}{\sum_{i=1}^{n}\left(t_{i}-\bar{t}\right)^{2}}
\end{array}\right.
$$

Among $\quad t=\frac{1}{n} \sum_{i=1}^{n} t_{i}, \bar{Z}=\frac{1}{n} \sum_{i=1}^{n} Z_{i} Z_{I}=\ln Y_{i}=\ln \left[\left.\frac{1}{y_{i}} \frac{d y}{d t}\right|_{t \rightarrow t_{i}}\right]$.

But because it only provides raw data $\left(t_{i}, y_{i}\right)$, and thus cannot be obtained $\left.\frac{d y}{d t}\right|_{t \rightarrow t_{i}}=$ $y^{\prime}\left(t_{i}\right)$, and therefore cannot calculate the $Z_{i}$ value. If we are based on the known $\operatorname{data}\left(t_{i}, y_{i}\right), \quad(i=1,2, \ldots n)$, find the approximate value of $y^{\prime}\left(t_{i}\right)$, so that you can find the approximation of $Z_{i}$ (We still use $Z_{i}$ to represent the approximate values of $\left.Z_{i}\right)$ This can be done by the data $\left(t_{i}, Z_{i}\right), \quad(i=1,2, \ldots n)$ substituting into (14)

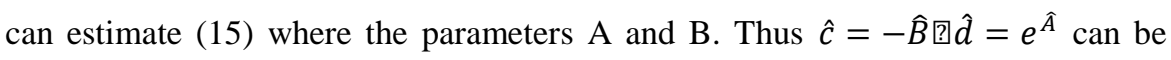
estimated, since $\hat{d}=\hat{b} \hat{c}$, so the estimated value of $\mathrm{b}$ is $\hat{b}=\frac{\hat{d}}{\hat{c}}=-\frac{e^{\widehat{A}}}{\widehat{B}}$. In this way, the two parameter in the model (9) is estimated. $\mathrm{b}$ and $\mathrm{c}$ produce a curve $y_{1}=$ $y_{1}(t)$ similar to the Gompertz curve to approximately replace the curve (9), then we derive the derivative $y_{1}=y_{1}(t)$ of the model (9) in $t_{i}$ with the derivative $y_{1 i}^{\prime}=$ $y_{1}^{\prime}\left(t_{i}\right)$ of $t_{i}$ from $y_{i}^{\prime}=y^{\prime}\left(t_{i}\right)$ (即 $y_{1 i}^{\prime} \approx y_{1}^{\prime}\left(t_{i}\right)=y_{i}^{\prime}$ ), we know that the Gompertz curve (9) is a growth curve, for which we can use the growth curve. But now the 
question is how to find $y_{i}^{\prime}=y^{\prime}\left(t_{i}\right)$, we use the curve fitting method:

$$
y_{1}=y_{1}(t)=\beta_{0}+\beta_{1} * t+\beta_{2} * t^{2}+\beta_{3} * t^{3}
$$

approximate instead of the Gompertz curve (9), so how to estimate (4) the four parameters $\beta_{0}, \beta_{1}, \beta_{2}, \beta_{3}$. This can be estimated by MATLAB based on the given data $\left(t_{i}, y_{i}\right), \quad(i=1,2, \ldots n)$.

Estimated by MATLAB $\widehat{\beta_{0}}, \widehat{\beta_{1}}, \widehat{\beta_{2}}, \widehat{\beta_{3}}$ substitution (16) type in:

$$
y_{1}=y_{1}(t)=\widehat{\beta_{0}}+\widehat{\beta_{1}} * t+\widehat{\beta_{2}} * t^{2}+\widehat{\beta_{3}} * t^{3}
$$

For (17) formula, the derivation of $\mathrm{t}$ is obtained:

$$
y_{1}^{\prime}=y_{1}^{\prime}(t)=\widehat{\beta_{1}}+2 * \widehat{\beta_{2}} * t+3 * \widehat{\beta_{3}} * t^{2}
$$

Let $y_{1 i}^{\prime}=y_{1 i}^{\prime}\left(t_{i}\right)=\widehat{\beta_{1}}+2 * \widehat{\beta_{2}} * t+3 * \widehat{\beta_{3}} * t^{2}$, then $y_{1 i}^{\prime}=y_{1}^{\prime}\left(t_{i}\right) \approx y_{i}^{\prime}=y^{\prime}\left(t_{i}\right)$, the parameter $\mathrm{b}$ and $\mathrm{c}$ in the (10) formula are estimated by the least square method, and the parameter $a$ in the estimate (9) formula is obtained.

\subsection{Fitting precision}

In the Gompertz curve regression equation problem, it is generally used to use the correlation index as the fitting precision, that is, the test:

$$
R^{2}=1-\frac{\sum_{i}^{n}\left(y_{i}-\hat{y}_{i}\right)^{2}}{\sum_{i}^{n}\left(y_{i}-\bar{y}\right)^{2}}
$$

the size of. The fitting accuracy of the curve is $R^{2}$, that is, the closer the $R^{2}$ is to 1 , the better the fitting accuracy of the curve.

\section{Result}

First, the parameter of $a$ is estimated as $a=317.6852$ according to the formula of the three-point method (6), and then the parameters of b and $c$ are estimated. According to the general method of Gompertz curve parameter estimation, that is, by least squares solution $\mathrm{B}=-0.2598, \mathrm{~A}=1.3135$, so $\mathrm{b}=3.7193, \mathrm{c}=$ 0.2598 , Therefore Gompertz curve equation is:

$$
y=317.6852 e^{-3.7193 e^{-0.2598 t}}
$$

The fitting accuracy $R_{1}^{2}, R_{1}^{2}=1-\frac{479.662}{51517.26}=0.990689$ is calculated by the formula (19)

The Gompertz curve equation yields the following Table 2:

Table 2. 3 To 12 Weeks old mice body weight and predicted body weight.

\begin{tabular}{lcccccccccc}
\hline Week age /t & 3 & 4 & 5 & 6 & 7 & 8 & 9 & 10 & 11 & 12 \\
\hline Body mass /y & 44.3 & 82.9 & 122.8 & 151.5 & 172.5 & 210.4 & 227.3 & 242.5 & 255.3 & 262.9 \\
Predicted body mass /y & 57.7 & 85.2 & 115.2 & 145.3 & 173.7 & 199.5 & 221.9 & 240.9 & 256.6 & 269.5 \\
\hline
\end{tabular}


Through the MATLAB software drawing three point method fitting curve 1:

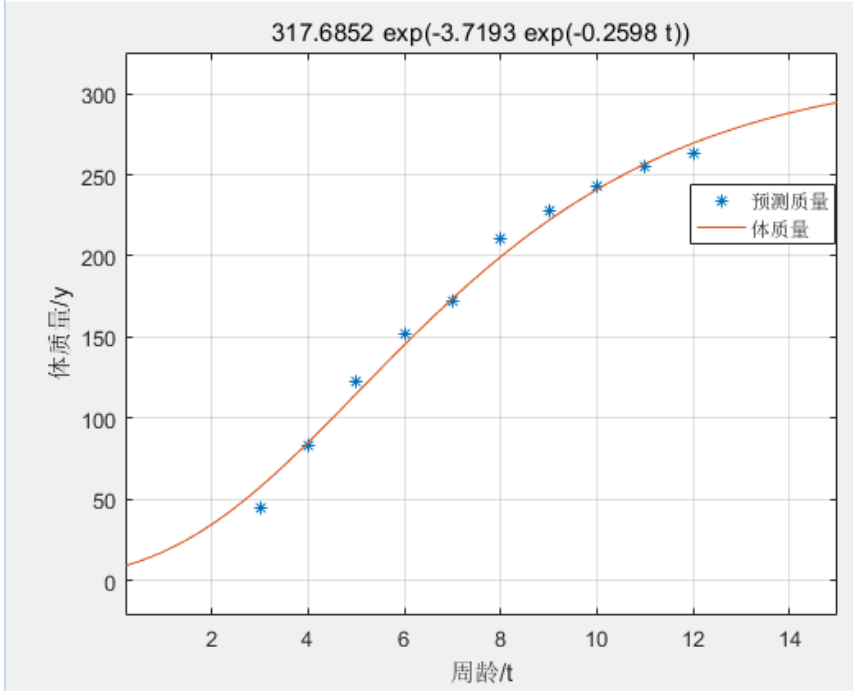

Fig. 1. Three-point fitting curve

Secondly, the Gompertz curve parameters are estimated by derivative method. The parameters $\widehat{\beta_{0}}, \widehat{\beta_{1}}, \widehat{\beta_{2}}, \widehat{\beta_{3}}$ in the growth curve (15) are estimated by MATLAB program, the value of $\widehat{\beta_{0}}=-85.9782, \widehat{\beta_{1}}=46.8802, \widehat{\beta_{2}}=$ $-0.9559, \widehat{\beta_{3}}=-0.0440$, its value into the formula (18) in the:

$$
y_{1}^{\prime}=y_{1}^{\prime}(t)=46.8802-2 * 0.9559 * t-3 * 0.0440 * t^{2}
$$

By a series of derivatives of the formula can be obtained $\mathrm{B}=-0.3797, \mathrm{~A}=$ $0.8106, \mathrm{~d}=2.2492, \mathrm{~b}=5.9235, \mathrm{c}=0.3797$, so the equation is:

$$
y=a e^{-5.9235 e^{-0.3797 t}}
$$

By the least squares method can be obtained $\mathrm{B}=-5.6229, \mathrm{~A}=5.6140, a=$ 274.2281, so the equation is:

$$
y=274.2281 e^{-5.9235 e^{-0.3797 t}}
$$

The fitting accuracy $R_{2}^{2}, R_{2}^{2}=1-\frac{322.8028}{51517.26}=0.993734$ is calculated by the formula (19).

Use the formula instead of the derivative of the Gompertz curve, use its value to represent the derivative value of the Gompertz curve, can be obtained in Table 3 below:

Table 3. 3 12 Weeks old mice body weight and predicted body weight.

\begin{tabular}{lcccccccccc}
\hline Week age $/ \mathrm{t}$ & 3 & 4 & 5 & 6 & 7 & 8 & 9 & 10 & 11 & 12 \\
\hline Body mass /y & 44.3 & 82.9 & 122.8 & 151.5 & 172.5 & 210.4 & 227.3 & 242.5 & 255.3 & 262.9 \\
Predicted body mass /y & 41.2 & 75.0 & 112.9 & 149.5 & 181.0 & 206.4 & 225.8 & 240.1 & 250.4 & 257.7 \\
\hline
\end{tabular}

Through the MATLAB software drawing three-point method fitting curve 2: 


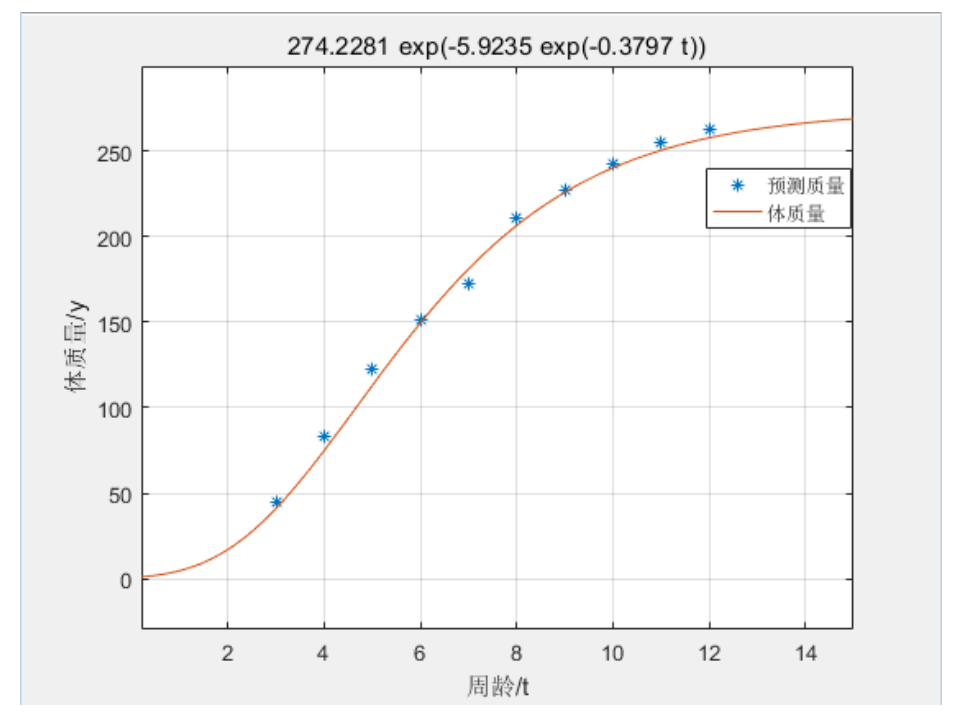

Fig. 2.fitting curve of derivative method

\section{Conclusion and discussion}

From the fitting accuracy and image contrast, $R_{1}^{2}<R_{2}^{2}$, obviously, in mouse growth prediction, the derivative method of the Gompertz curve parameter is better than the general method of the Gompertz curve parameter, and is more suitable for statistical analysis of mice and can be used for mouse growth estimation and prediction.

The growth curve equation is used to summarize the information distributed to each sample point to a few parameters, the characteristics of the growth process can be described, the production process of the mice can also be predicted according to their curves, this has a lot of usefulness for making production plans, predicting selection reactions, and performing genetic analysis of growth processes. And for genetics, physiology nutrition and other disciplines to provide a new way and basis.

Yang Ning and other quail on the growth curve analysis, found that the parameters of the gender effect and its significant [8], in mice is also the case, pending further study and analysis.

\section{References}

1. Cheng L, Lu X Y, Wang Q Z. Development and trend analysis of growth and development curve of $\mathrm{Hu}$ sheep [J]. Chinese Journal of Animal Husbandry and Veterinary Medicine,2014, 12: 239-243

2. Fu J. Interspecific mouse growth curve fitting $[\mathrm{J}]$ Zhejiang Animal Science and Veterinary Medicine, 2000,2（2） : 6-7

3. Yang M H, Xu Q, Dai G J. Analysis of three commonly used growth curves for poultry [J]. Chinese poultry, 2004,8 (1) : 164-166

4. Liu E Q, He Y X, Bai F E. BALB / c mouse growth curve analysis [J]. Beijing 
Experimental Animal Science, 1992,9 (1) : 15-16

5. Wang J F, Shi M L, Wu Y Q. Determination of growth curve, main organ parameters and physiological and biochemical indexes of GF grade KM mice [J]. Chinese Journal of Comparative Medicine, 2012，22（3）: 17-22

6. Xi X X, Cheng J, Tian Y G. Determination of growth curve and weight of main organs of three SPF mice [J]. Animal and Veterinary Medicine of Heilongjiang Province,2012,1 (1) : $136-138$

7. Zheng M E, Li L, Wu S L. Bertanlanffy model analysis of six SPF - size mouse growth curves [J]. Laboratory Animal Science, 2015, 8 (4) :11-12

8. Yang N. Analysis on Growth Curve of Quail in Different Strains. The 4th National Symposium on Poultry Symposium, in 1989 